polyclinic could contact a dual-trained consultant for advice or consultation, possibly via a telemedicine link. A polyclinic should be able to provide a second opinion to a GP with the patient returned with a diagnosis and treatment plan (including a risk or relapse plan).

St John-Smith et al are right to point out the finite number of community mental health team (CMHT) staff. Perhaps CMHT staff and primary care mental health staff would need to be seconded for these triaging duties including an appropriate shift pattern to avoid burnout. General practice registrars will find triaging experience particularly relevant for their future role (which might include competency to work as a GP with a special interest).

We live and work in uncertain times. I suspect most of the politics that surround secondary care mental health is influenced by fears of job losses (particularly managerial) in this financial climate, worsened by lack of clarity on payment by results in terms of the relative priority given to new assessments compared with continuing secondary care. Hopefully, these matters will be resolved over the next 18 months, but in the meantime it is well worth studying successes in other medical fields to inform the next wave of reforms, most likely driven by a new set of clinical commissioners from primary care.

1 St John-Smith P, McQueen D, Michael A, Ikkos G, Denman C, Maier M, et al. The trouble with NHS psychiatry in England. Psychiatr Bull 2009; 33 219-25.

Prasanna N. de Silva Consultant Psychiatrist, Tees, Esk and Wear Valleys NHS Foundation Trust, Whitby Hospital, Springhill,Whitby, email: prasanna.desilva@ tewv.nhs.uk

doi: 10.1192/pb.33.9.356b

\section{New ways can work}

Much is being made of the negative effects of New Ways of Working, to the extent that its future is now seriously threatened despite the fact that viable or palatable alternatives have not been proposed within an environment of increasing service demand.

Having experienced working in several trusts through the process of adopting New Ways of Working (in working and older age adults), my belief is that the current challenge lies in identifying which factors lead to success and which do not. The next question is whether the successful factors can be systematised (i.e. are not entirely dependent on individual skill, knowledge or enthusiasm). My view is that the following three factors are of key importance.

1. NewWays of Working needs to be clinically led and not perceived as being misappropriated by management for their own (financial?) agenda.
2. Strong team leadership to encourage and support care coordinators' increased responsibilites

3. Boundaries between functional teams need to be explicit, without the gaps that general practitioners hate, and with great emphasis on excellent, protocolled communication standards. Universality and continuity of service delivery are thus ensured.

New Ways of Working remains in an experimental phase and shows promise. We cannot allow naysayers whose fear of obsolescence or displacement from power hold back real progress. New ways can work. Isn't it time for the College to canvass members to find out how?

David J. Ogden Consultant Psychogeriatrician, email: david.ogden@glos.nhs.uk

doi: 10.1192/pb.33.9.357

\section{New ways of losing the art of psychiatry}

As a consultant working in a tertiary service I see the results of New Ways of Working rather than participating directly myself. What emerges is a loss of diagnosis, let alone any attempt at a differential.

New Ways of Working assumes that it is easy to tell, at the moment of referral, whether or not a problem is complex or straightforward. In reality, overt psychosis can be relatively straightforward to spot but such individuals go to a psychiatrist. Left undiagnosed are complex personality disorder (borderline pathology reduced to 'depression') and subtle or unusual psychotic states such as encapsulated delusions or thought disorder, described as 'normal'.

I have been involved in an increasing number of cases where there have been serious consequences of misdiagnosis, of the type that used to shame a part 1 candidate for MRCPsych. Diagnosis is still considered a fundamental part of medicine, so why have we, apparently willingly, opted out of this aspect of our medical discipline? I concur with those who worry about the demise of psychiatry what is the point of a discipline that seemingly anyone can practice? The loss of differentiation between the disciplines does not contribute to egalitarian practice, it only leads to non-specific and perhaps unhelpfully focused treatment.

Cleo Van Velsen Consultant Psychiatrist in Forensic Psychotherapy, East London NHS Foundation Trust, John Howard Centre, 12 Kenworthy Rd, Hackney E9 5TD, email: lorraine.collins@chcst. nthames.nhs.uk

doi: 10.1192/pb.33.9.357a

\section{Problems in NHS psychiatry and recruitment chaos - are they related?}

The article 'The trouble with NHS Psychiatry in England ${ }^{1}$ coincided with the Dean of the Royal College of Psychiatrists Professor Howard's interview on Channel 4 news on 4 June $2009 .^{2}$ The very fact that psychiatry is one of the least favoured specialties for UK medical graduates suggests that there is trouble with NHS psychiatry in the UK. Perhaps the College and its members need to look at the possible reasons. ${ }^{3}$

The College has already been dealing with stigma that psychiatry and psychiatry patients face. It appears that many recent medical graduates secured a psychiatry post as part of their foundation training on the basis of favourable placements as a medical student ${ }^{4}$ at the time of 'old' ways of working. Unfortunately, their subsequent experience with the 'new' ways of working for psychiatrists has been less reassuring. They have often noticed psychiatrists being marginalised and their role being reduced to firefighting with a lack of proactive interventions. This has led to many medical graduates deciding not to take up a career in psychiatry or even to seek higher training in psychiatry abroad.

Medical graduates are often attracted to various specialties by role models. ${ }^{5} \mathrm{We}$ wonder whether a relative lack of role models is the reason for UK graduates not opting for psychiatry. In his interview on Channel 4 news, Professor Howard suggested that psychiatry is being forced to recruit trainees who just meet the minimum criteria. This might lead to fewer role models in psychiatry, further recruitment problems and more trouble.

Perhaps the College might consider introducing 'newer' ways of working, recruiting and training.

1 St John-Smith P, McQueen D, Michael A, Ikkos G, Denman C, Maier M, et al. The trouble with NHS psychiatry in England. Psychiatr Bull 2009; 33 : 219-25.

2 Hannam L, Wivell J. Psychiatry's UK recruitment crisis. Channel 4 News 2009; 4 June (http://www. channel4.com/news/article.jsp?id=3190557).

3 Kerby J, CaltonT, Dimambro B, Flood C Glazebrook C. Anti-stigma films and medical students? attitudes towards mental illness and psychiatry: randomised controlled trial. Psychiatr Bull 2008; 32: 345-9.

4 Eagles JM, Wilson S, Murdoch JM, BrownT. What impact do undergraduate experiences have upon recruitment into psychiatry? Psychiatr Bull 2007; 31: $70-2$

5 Wright S, Wong A, Newill C. The impact of role models on medical students. J Gen Intern Med 1997: 12: 53-6.

*Venkata B. Kolli ST3 Adult Psychiatry, Wedgwood House, Suffolk Mental Health Partnership NHS Trust, Hardwick Lane, Bury St Edmunds, Suffolk IP33 2QZ, email: venkata.kolli@smhp.nhs.uk, Jonathan Lyons CT1 Old Age Psychiatry, Danica Ralevic ST3Old Age Psychiatry, Wedgwood House, Suffolk Mental Health Partnership NHS Trust

doi: 10.1192/pb.33.9.357b 